\title{
Erratum
}

\section{Erratum to "Bridging the Gap between Economic Modelling and Simulation: A Simple Dynamic Aggregate Demand-Aggregate Supply Model with Matlab"}

\author{
José M. Gaspar (iD) ${ }^{1,2}$ \\ ${ }^{1}$ Católica Porto Business School, Universidade Católica Portuguesa, Porto, Portugal \\ ${ }^{2}$ CEF.UP, University of Porto, Porto, Portugal \\ Correspondence should be addressed to José M. Gaspar; jgaspar@porto.ucp.pt
}

Received 26 February 2018; Accepted 13 March 2018; Published 21 June 2018

Copyright (C) 2018 José M. Gaspar. This is an open access article distributed under the Creative Commons Attribution License, which permits unrestricted use, distribution, and reproduction in any medium, provided the original work is properly cited.

In the article titled "Bridging the Gap between Economic Modelling and Simulation: A Simple Dynamic Aggregate Demand-Aggregate Supply Model with Matlab" [1], an incomplete version of the Supplementary Materials was published. Also, there was a typographical error in the numerical evaluation section, where the word "supplemantary" should be corrected to "supplementary." This occurred due to production errors. The complete updated version of the Supplementary Materials is available here.

\section{Supplementary Materials}

The Matlab code is embedded in a single function (ADASdynamic.m). Add the ".m" file to the working Matlab path/directory. Open Matlab and run the name of the file in the command window (ADASdynamic). The programme asks the user to introduce values for the parameters described throughout the paper, including the initial time and final time. It then produces three figures: one is for the solution $y(t)$, another is for both $\pi^{e}(t)$ and $\pi(t)$, and the last one shows the phase diagram portraying the transition dynamics. The programme will then ask the user to implement either monetary, fiscal, supply side shocks, or any possible combination of shocks, by introducing new values for the money growth rate, public spending, tax rate, and level of natural output. This will produce three new graphs, with the same information as described previously, but compared to the initial situation. Therefore, the figures shown after implementing shocks will portray the global transition dynamics towards the new equilibrium. Along these processes, the output for the relevant steady-state levels and their qualitative properties are shown in Matlab's command window, along with the parameter values. See Appendix B for an example of how the output is displayed in Matlab's command window. (Supplementary Materials)

\section{References}

[1] J. M. Gaspar, "Bridging the gap between economic modelling and simulation: a simple dynamic aggregate demand-aggregate supply model with Matlab," Journal of Applied Mathematics, vol. 2018, Article ID 3193068, 13 pages, 2018. 


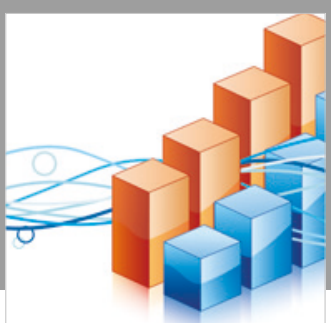

Advances in

Operations Research

\section{-n-m}
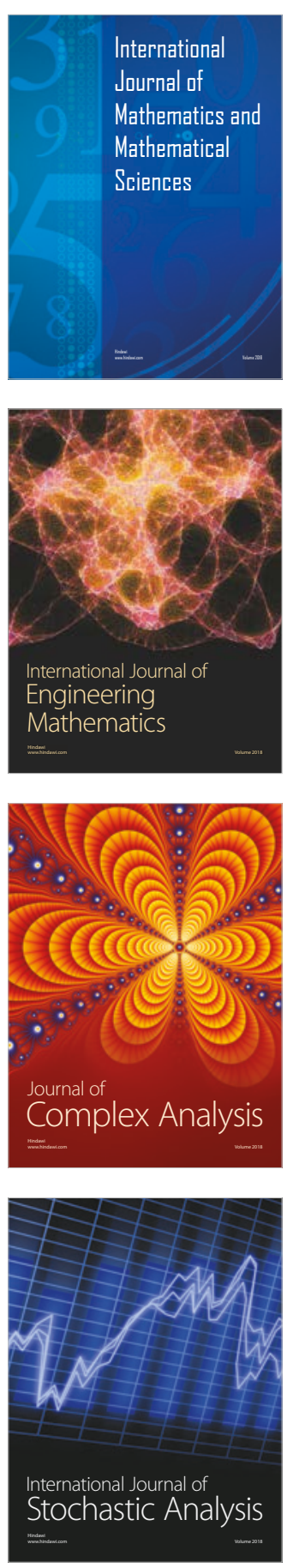
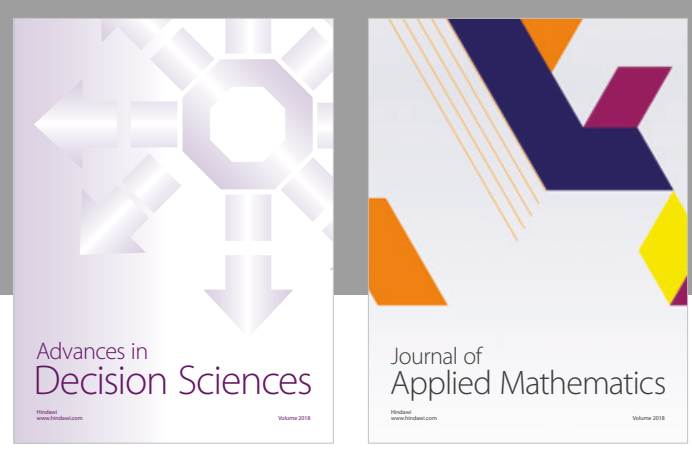

Journal of

Applied Mathematics
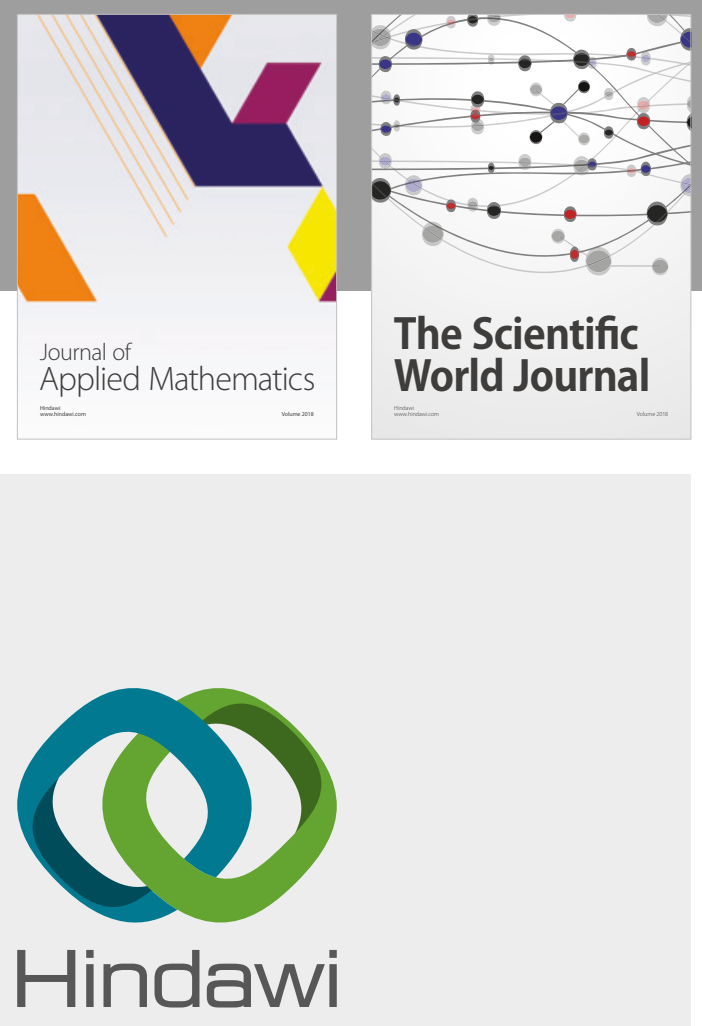

Submit your manuscripts at

www.hindawi.com

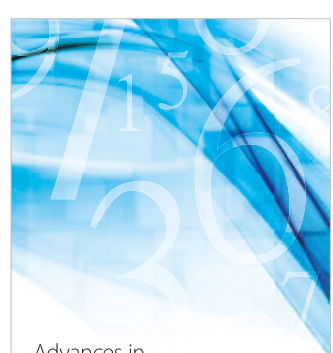

Advances in
Numerical Analysis
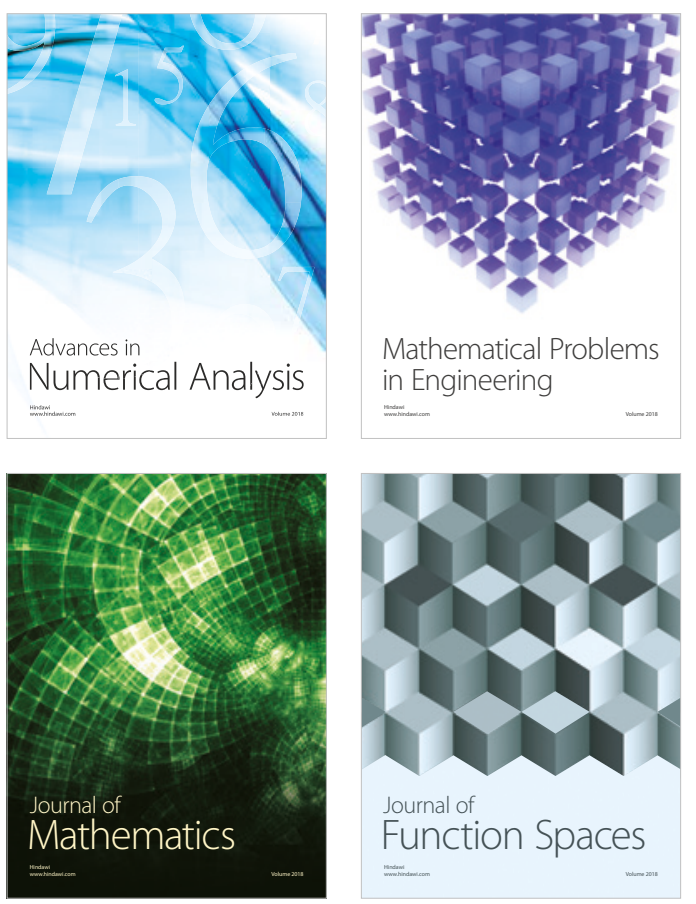

Mathematical Problems in Engineering

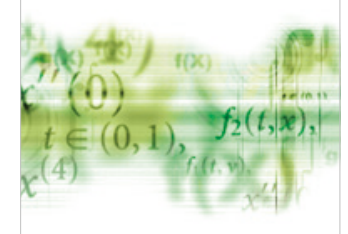

International Journal of

Differential Equations

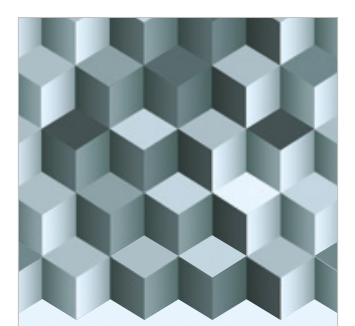

Journal of

Function Spaces

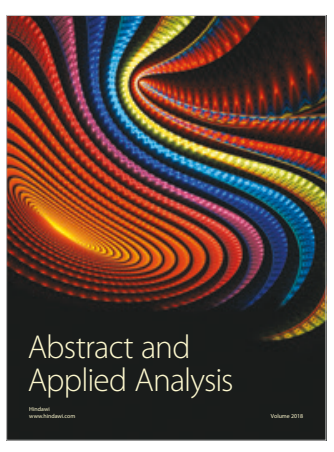

The Scientific

World Journal

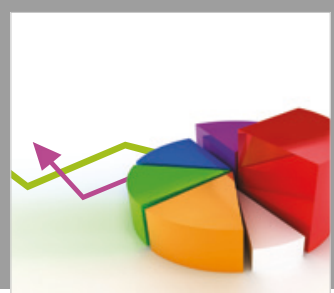

Journal of

Probability and Statistics
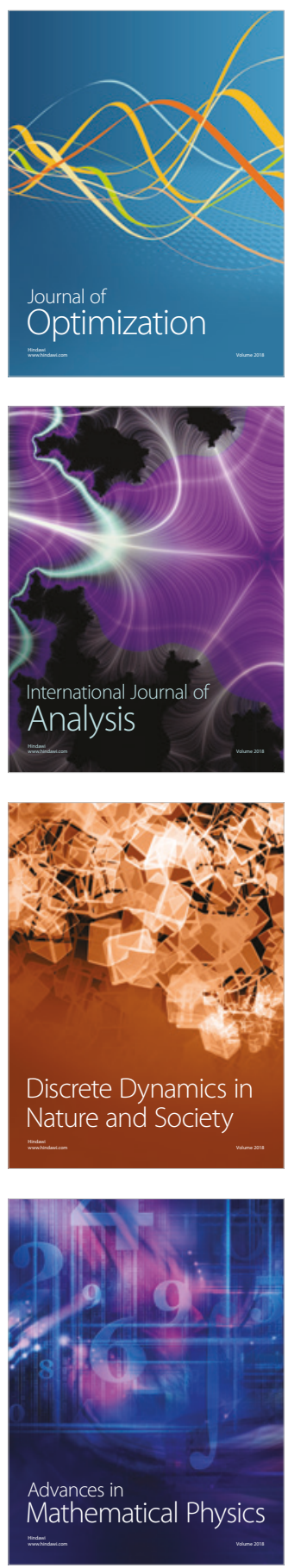